\title{
Numerical Simulation of Solar Air Heater using Paraffin Wax-Aluminum Compound as Phase Changing Material
}

\author{
Atul Kumar ${ }^{1}$, Prabhakar Bhandari ${ }^{2}$, K.S. Rawat ${ }^{3}$ \\ ${ }^{1}$ Mechanical Engineering department, IFTM University, Moradabad, Uttar Pradesh, India \\ ${ }^{2}$ Mechanical Engineering department, NIT Uttarakhand, Srinagar Garhwal, India \\ ${ }^{3}$ Department of Mechanical Engineering, MIET, Meerut-250005, India \\ e-mail: akres9017@gmail.com ${ }^{1}$, prabhakar.bhandari40@gmail.com ${ }^{2}$ kamal.rawat@miet.ac.in ${ }^{3}$
}

Kumar, A. ., Bhandari, P., \& Rawat, K. . (2021). Numerical Simulation of Solar Air Heater using Paraffin Wax-Aluminum Compound as Phase Changing Material. Aptisi Transactions on Technopreneurship (ATT), 3(2), 49-55.

DOI: https://doi.org/10.34306/att.v3i2.199

\begin{abstract}
This paper presents a theoretical investigation of solar air heaters using phase change material (PCM). PCM used in present configuration is homogenous mixture of paraffin wax with Aluminium powder. The purpose of using Aluminium powder with paraffin wax is to increase the thermal conductivity. PCM mixtures are encapsulated in cylinders and are used as solar absorbers. Using the MATLAB program, the effect of different parameters is studied. It has been observed that with increase in mass flow rate, air outlet temperature decreases and freezing time of cylinder decreases. However, at constant mass flow rate, with increase in cylinder radius, air temperature decreases and while freezing time increases sharply. The different parameters have to be chosen such that performance of the solar air heater can be optimized.
\end{abstract}

Keywords: Solar Air Heater, Phase Changing Material, Paraffin Wax, Aluminum, Freezing time.

\section{Introduction}

Solar energy is a clean and green energy which is available on the earth for an entire year. Utilization of solar energy gains attention as conventional sources of energy are depleting and they are also responsible for pollution and global warming [1]. Solar energy can be utilized for different applications i.e. space heating, water heating, crop drying and electricity generation. In recent years, the use of solar energy in solar air heaters (SAH) has gained much attention. SAH absorbs the solar radiation by means of an absorption surface and absorbed thermal energy is transferred to a fluid which can be air, water, or nanofluid [2-5].

SAHs are simple and flexible in design; they have low cost and require less maintenance [6]. However, the absorber surface of SAH has a very low heat transfer coefficient with air due to which its efficiency is low [7]. Many researchers proposed various surface roughness patterns and techniques to improve the performance and efficiency of SAH [8-11]. Apart from that some researchers also suggest the use of phase change materials (PCM) to absorb the heat in the form of latent heat [12-13].

Due to the intermittent nature of solar energy, researchers have more on storage methods and materials. Farid et al. [14] reviews the material used as phase change material (PCM) like hydrated salts, fatty acids, paraffin, eutectics of organic and inorganic compounds.

Author Notification 08 August 2021 Final Revised 26 August 2021 Published 14 September 2021 
Major problem associated with PCM is low thermal conductivity. Researchers tried to enhance the thermal conductivity of PCM with the help of additives like Aluminum powder [15] or using extended surfaces (fins) [16].

Uses Al powder with paraffin wax in the water base collector and found an increase in heat gain compared to only paraffin [17]. In present work, air temperature along the channel and freezing time of PCM units has been evaluated under different operating conditions. A $M A T L A B$ program has been developed to compute the different values.

\section{Literature Review}

This system consists of three essential parts which are: a single transparent glass, isolated duct and the storage unit which is consist of a single row of cylinders contain a PCM, the cylinders placed in the crossflow of forced air stream, this unit works to satisfy two goals; absorb and storage the solar energy.

The dimensions of the collector are $0.1808 \mathrm{~m} \times 1.06 \mathrm{~m} \times 2 \mathrm{~m}$. It has aluminium cylindrical containers as an absorber which are painted black. The design is taken into consideration for concerns like integration with the PCM storage unit, the simplicity of construction, dismantlement, and handling the PCM unit. A reflector sheet adjusted under the cylinders to reflect the escaped rays through the spaces between them. A solar simulator charges the collector by thermal energy until the cylinders became at liquid phase, there is no conflict between charging and discharging, and are assumed to take place at different times so, to investigate the output air temperature due to discharge process consider that no radiation.

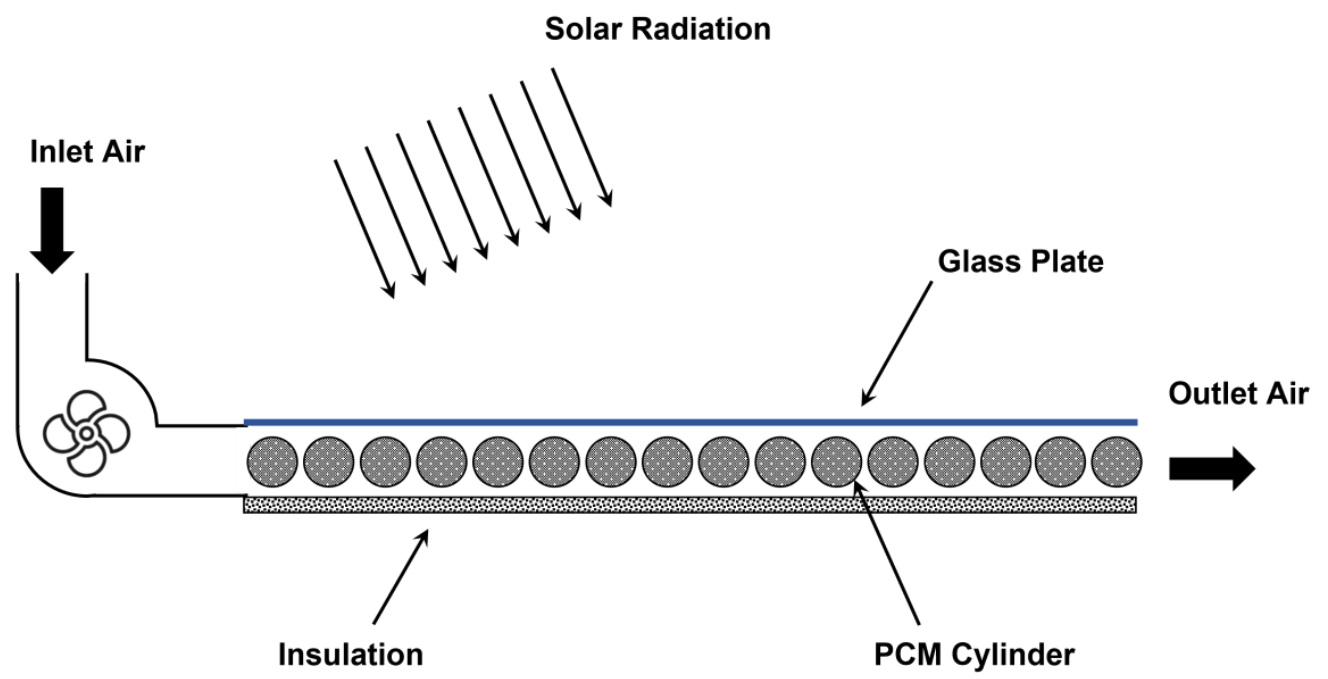

Fig 1. Cross section of the Solar Air Collector with PCM Cylinders.

\section{Mathematical Modeling}

In order to predict air temperature and freezing time, various assumptions have been employed to simplify the process. These assumptions are as follows:

a) Properties of air and PCM are kept as constant and are not varied with temperature.

b) Heat loss is assumed to be very low and is therefore neglected.

c) Heat flow through each cylinder is in radial direction through conduction only.

d) Air is treated as incompressible fluid.

It was observed that paraffin wax has lower thermal conductivity, so to improve it Aluminum powder has been also mixed homogeneously. It is assumed that Aluminum powder has particle size less than $100 \mu \mathrm{m}$. The thermo-physical properties of wax-Al mixture are calculated in equation (1)-(3). 


$$
\begin{aligned}
& K_{c}=K_{p . w} v_{p . w}+K_{A l} v_{A l} \\
& C_{c}=C_{p . w} m_{p . w}+C_{A l} m_{A l} \\
& \rho_{c}=\rho_{p . w} v_{p . w}+\rho_{A l} v_{A l}
\end{aligned}
$$

Where, $K_{c}, c_{c}, \rho_{c}$ are thermal conductivity, specific heat and density of new mixture respectively.

In the above equations, $v$, and $m$ are volume fraction and mass fraction and are calculated as follows:

$$
\begin{aligned}
& v_{p . w}=\frac{V_{p w}}{V_{C}} \\
& v_{A l}=\frac{V_{A l}}{V_{C}}
\end{aligned}
$$

$$
\begin{aligned}
& m_{p . w}=\frac{M_{p w}}{M_{C}} \\
& m_{A l}=\frac{M_{A l}}{M_{C}}
\end{aligned}
$$

Suffix $A l$ and $p, w$ denote Aluminium powder and paraffin wax.

Table 2. Values of different properties taken in study

\begin{tabular}{|c|c|c|c|}
\hline & Paraffin wax & Aluminum & New compound \\
\hline$\left(T_{c r}\right)$ & $50^{\circ} \mathrm{C}$ & - & $50^{\circ} \mathrm{C}$ \\
\hline$(H)$ & $190 \mathrm{KJ} / \mathrm{kg}$ & - & $190 \mathrm{KJ} / \mathrm{kg}$ \\
\hline$(P)$ & $930 \mathrm{~kg} / \mathrm{m}^{3}$ & $2707 \mathrm{~kg} / \mathrm{m}^{3}$ & $933 \mathrm{~kg} / \mathrm{m}^{3}$ \\
\hline$(K)$ & $0.21 \times 10^{-3} \mathrm{KW} / \mathrm{mK}$ & $0.204 \mathrm{KW} / \mathrm{mK}$ & $0.56 \mathrm{KW} / \mathrm{mK}$ \\
\hline$(C)$ & $2.1 \mathrm{KJ} / \mathrm{kg}$ & $0.896 \mathrm{KJ} / \mathrm{kg}$ & $2.09 \mathrm{KJ} / \mathrm{kg}$ \\
\hline
\end{tabular}

Energy balance has been carried out for each cylinder

$$
\left(T_{\text {in }}-T_{\text {out }}\right) C_{a} m_{a}=2 \pi R_{o} \operatorname{lh}\left(T_{\text {in }}-T_{\text {sur }}\right)
$$

Where, $m_{a}$ is mass flow rate of air which varies from 0.05 to $0.21 \mathrm{~kg} / \mathrm{s}$. Specific heat of air $\left(C_{a}\right)$ is taken as $1009 \mathrm{~J} / \mathrm{kg} . \mathrm{K}$.

$$
T_{j+1}=\gamma T_{c r}+T_{J}(1-\gamma)
$$

Where $\mathrm{J}$ varies from 1 to $\mathrm{N}$.

Freezing time for the Wax-Al mixture in each cylinder is

$$
t_{J}=\omega[1+(J+1) \gamma]
$$

Where 
$\omega=\frac{R_{o}^{2} H \rho}{2 K_{s} \Delta T}\left[\frac{1}{2}+\frac{K_{s}}{h R_{o}}\right]$

$\omega=\frac{2 \pi R_{o} l h}{c_{a} m_{a}}$

Fluid temperature $T_{J}(t)$ after $\mathrm{J}$ cylinder is approximately:

$T_{S}, t_{J}<t$

$T_{J-1}, t_{1}<t \leq t_{2}$

$T_{J-2}, t_{2}<t \leq t_{3}$

$T_{S}, t_{J}<t$

Heat transfer coefficient for cylinders has been calculated using McAdams expressions(1954).

$h=\frac{K_{a}}{D_{o}} b_{2} \operatorname{Re}^{n}$

Where $b_{2}$ and $n$ are constants having value of 0.3 and 0.6 respectively

A program has been formed in MATLAB 2009 for computing the results. MATLAB 2009 has been used as it offers a very user friendly environment and is an integrated technical computing environment that combines numeric computation, advanced graphics and visualization, and a high level programming language. It is more than a fancy calculator and is an extremely useful and versatile tool.

\section{Results and Discussion}

The results obtained after performing numerical simulations for different working conditions are illustrated here with discussions. The parameters that have been varied are mass flow rate and cylinder radius.

The variation of air temperature along the collector length for different mass flow rate of air has been shown in fig. 2. Air temperature has been measured after each PCM cylinder and is depicted in fig. 2. It is observed from the plot that with increase in mass flow rate, air temperature decreases throughout the channel length irrespective of the cylinder. This is because the amount of heat being carried by air is same and with the increase in mass flow rate, less temperature gain is observed in air.

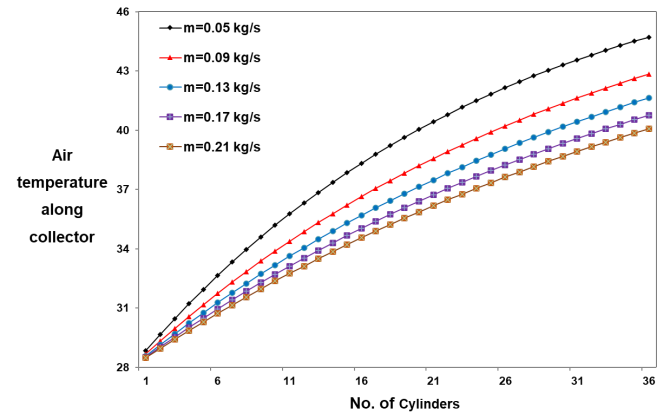

Fig 2. Variation of Air Outlet Temperature with Number of Cylinder For Different Mass Flow

Rate 
Figure 3 shows the variation of time required in freezing of different cylinders with mass flow rate. When the mass flow rate increases, there is a decrease in freezing time. For mass flow rate of $0.5 \mathrm{~kg} / \mathrm{s}$, freezing time for the 1st cylinder is $8.3 \mathrm{hr}$ which is nearest to the inlet and while for the last cylinder is $18.7 \mathrm{hr}$. While the lowest freezing time was observed for mass flow rate of $0.21 \mathrm{~kg} / \mathrm{s}$. Moreover, it is also observed that with the increase in mass flow rate, the slope of the freezing plot increases continuously.

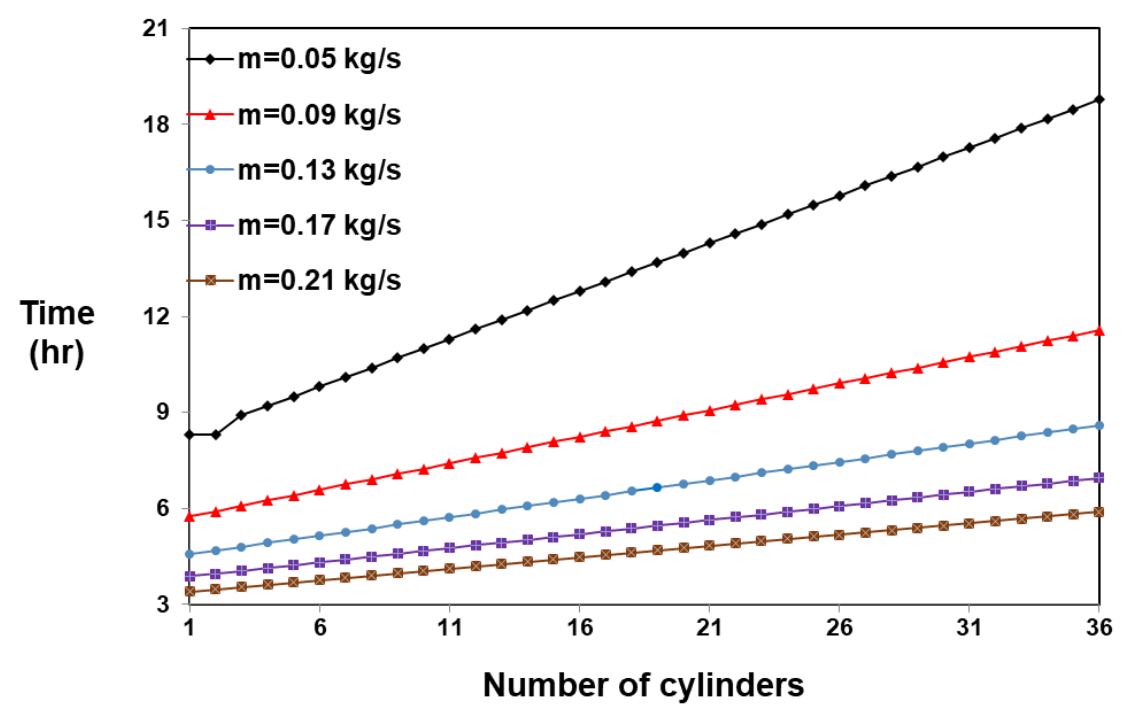

Fig 3. Variation of Time with Number of Cylinder for Different Mass Flow Rate

Now keeping the mass flow rate constant, cylinder radius has been varied. Figure 4 shows the variation of air temperature along the channel length for different cylinder radius. Smaller cylinder has shown less disturbance in the air flow field and therefore has a higher temperature compared to a larger cylinder. The temperature will decrease to increase the radius of the cylinder at inlet and outlet. For $0.005 \mathrm{~m}$ cylinder radius, air temperature at inlet and outlet was $28.9^{\circ} \mathrm{C}$ and $45.5^{\circ} \mathrm{C}$ and while for $0.035 \mathrm{~m}$ cylinder, temperature observed was $28.87^{\circ} \mathrm{C}$ and $44.92^{\circ} \mathrm{C}$ respectively.

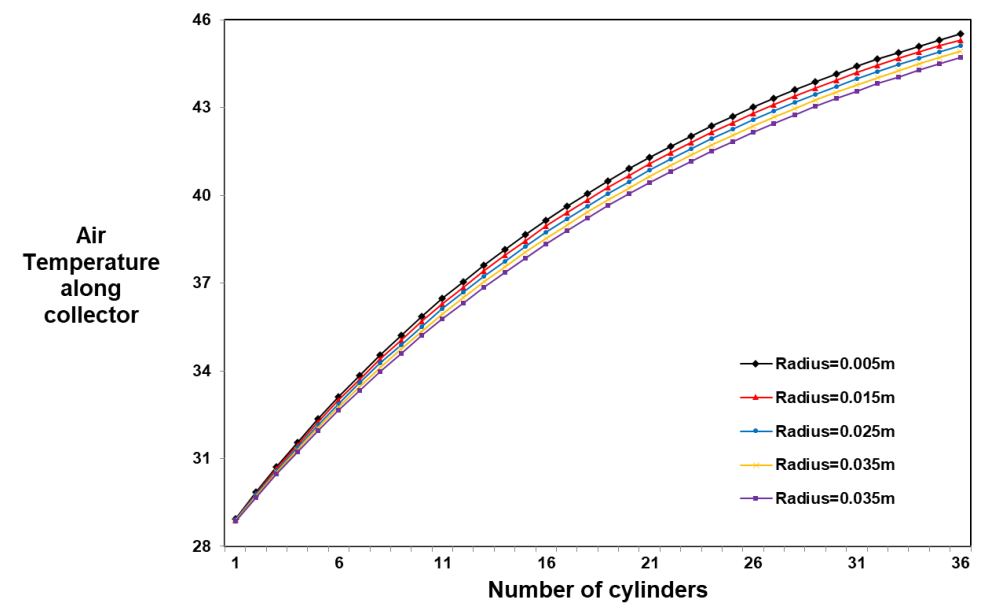

Fig 4. Variation of Air Temperature Along the Collector Length for Different Cylinder Radius 
With the increase in cylinder radius, freezing time increases at a much higher rate as depicted in fig 5. This can be attributed to more PCM has to freeze with increase in cylinder radius.

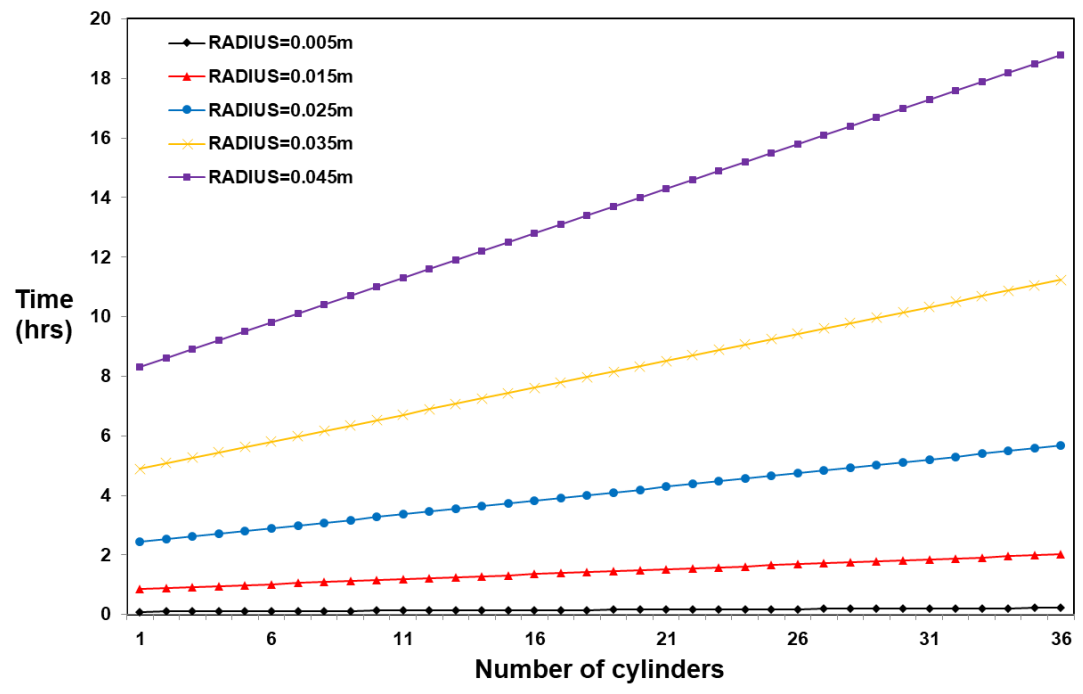

Fig 5. Effect of cylinder radius on freezing time

\section{Conclusion}

The present numerical study has been carried out using a solar air heater using paraffin- wax Aluminium compound as a thermal storage material enclosed in a cylinder. The objective of present work is to determine effects of various parameters like mass flow rate and cylinder radius on the performance. A MATLAB program has been made and simulated under different operating conditions. On the basis of results, the following conclusions can be drawn:

1. It has been found that with increase in mass flow rate, air outlet temperature decreases and freezing time of cylinder decreases.

2. With increase in cylinder radius, air temperature decreases and while freezing time increases sharply.

3. To optimize the performance of configuration, the proper selection of parameters has to be done.

\section{References}

[1] H.M.S. Al-Maamary, H.A. Kazem, M.T. Chaichan, Changing the energy profile of the GCC States: A review, Int. J. Appl. Eng. Res. 11 (3), 1980-1988 (2016).

[2] M. Mahesh, S.K. Bhor, B.R.V. Bharat, Enhancement of heat transfer rate and thermal efficiency of solar air heater by using flow turbulators-a review, Int. J. Innovative Res. Sci. 4 (1) (2015) 18450-18455.

[3] P. Bhandari, L. Varshney, \& V.S. Bisht, Numerical analysis of Hybrid Solar Water Heating System Using Wire Screen Packed Solar Air Heater. 1st International Conference on New Frontiers in Engineering, Science \& Technology, Vol. 1, 415-1422 (2018).

[4] L. Varshney, P. Bhandari, \& V.S. Bisht, Performance Evaluation of Hybrid Solar Water Heating System Using Wire Screen Packed Solar Air Heater. Int. Journal of Engineering Research and Application (IJERA), 311-316(2014).

[5] N. Kumar, P. Singh, A.K. Redhewal, P. Bhandari, A Review on Nanofluids Applications for Heat Transfer in Micro-channels. Procedia Eng., vol. 127, pp. 1197-1202 (2015). 
[6] D. Zhang, J.P. Li, Y.J. Cho, I. Wang, J. Nan, Thermal performance investigation of modified flat plate solar collector with dual-function, Appl. Therm. Eng. 108 (2016) $1126-1135$.

[7] B. Jia, F. Liu, D. Wang, Experimental study on the performance of spiral solar air heater, Sol. Energy 182 (2019) 16-21.

[8] Gangwar HP, Rawat KS, Pratihar AK. Heat Transfer Studies in an artificial roughened solar air heater having wire rib roughness. International journal of Pure and Applied Mathematics. 2018;119:1505-9.

[9] Bisht VS, Patil AK, Gupta A. Compact Solar Air Heater: A Review. Advances in Fluid and Thermal Engineering. 2019:273-81.

[10] R.K. Nayak, S.N. Singh, Effect of geometrical aspects on the performance of jet plate solar air heater, Sol. Energy 137 (2016) 434-440.

[11] Singh B.P., Bisht V.S., Bhandari P. (2021) Numerical Study of Heat Exchanger Having Protrusion and Dimple Roughened Conical Ring Inserts. In: Sikarwar B.S., Sundén B., Wang Q. (eds) Advances in Fluid and Thermal Engineering. Lecture Notes in Mechanical Engineering. Springer, Singapore.

[12] M.T. Chaichan, K.I. Abass, H.A. Kazem, Design and assessment of solar concentrator distillation system using phase change materials (PCM) suitable for desertec weathers, Desalination and water treatment 57 (32) (2016) 14897-14907.

[13] A.H.A. Al-Waeli, M.T. Chaichan, K. Sopian, H.A. Kazem, Experimental investigation of using nano-PCM/nanofluid on a photovoltaic thermal system (PVT): technical and economic study, Thermal Science and Engineering Progress 11 (2019) 213-230.

[14] Farid M. M., Khudhair A. M., Razack S. A. and Al-Hallaj S. 2004. A review on phase change energy storage: materials. Energy Conversion and Management. 45: 1597.

[15] Marín et al. Improvement of a thermal energy storage using plates with paraffin-graphite composite. International Journal of Heat and Mass Transfer. 48(2005), 2561-2570.

[16] V. Shatikian, G. Ziskind, and R. Letan. Numerical investigation of a PCM-based heat sink with internal fins: constant heat flux. International Journal of Heat and Mass Transfer. 51(2008), 1488-1493.

[17] S. Mettawee Eman-Bellah and M.R. Assassa Ghazy. Thermal conductivity enhancement in a latent heat storage system. Solar Energy. 81(2007), 839. 